\title{
Amending Invasion With Carbon: After Fifteen Years, a Partial Success
}

\section{By Peter Alpert}

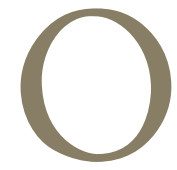

ne of the factors most strongly associated with high abundances of human-introduced plant species in natural and seminatural systems in North America and Europe is high availability of soil nutrients, particularly nitrogen (N)., ${ }^{1,2}$ For example, areas within grasslands or shrublands that have soils with higher levels of inorganic $\mathrm{N}$ tend to be more invaded than areas with lower levels; adding nutrients to grasslands experimentally often increases the absolute and relative abundance of introduced plants whose propagules are present; and the common introduced species in partly invaded grasslands often increase their growth more in response to high $\mathrm{N}$ than do the common native species when plants are grown separately.

This suggests that reducing the availability of $\mathrm{N}$ in the soil might slow or reverse the spread of introduced plants in grasslands. ${ }^{3,4}$ One relatively quick and specific, if probably temporary, way to do this is to promote the uptake of $\mathrm{N}$ by soil microbes by amending the soil with a metabolic substrate for bacteria or fungi that is very low in N, such as sucrose, cellulose, lignin, or most types of sawdust or other fine residue from the cutting or milling of wood. Since these substances are all high in carbon (C), the metabolic energy from them being derived largely from splitting $\mathrm{C}-\mathrm{C}$ bonds, this method has been commonly called "carbon addition," not to be confused with the use of activated, pure $\mathrm{C}$ to adsorb and reduce availability of organic compounds such as allelochemicals.

The generally accepted mechanism by which $\mathrm{C}$ addition to soil might reduce the abundance of introduced plants and promote the abundance of native ones involves not only competition for inorganic $\mathrm{N}$ between plants and microbes, but also competition between introduced and native plants as well as contrasting responses of introduced and native plants to availability of N (Fig. 1a). Reduction in supply of inorganic $\mathrm{N}$ due to uptake by microbes is expected to have a direct negative effect on natives. However, reducing $\mathrm{N}$ is also expected to have an indirect positive effect on natives, by negatively affecting introduced plants and reducing their negative effects on natives. If the response of introduced plants to $\mathrm{N}$ availability is greater than that of natives, the indirect positive effect on natives of reducing $\mathrm{N}$ could be greater than the direct negative effect. Adding $\mathrm{C}$ and fueling higher metabolism of microbes should then decrease inorganic N, decrease growth of introduced plants, and increase growth of natives (Fig. 1b). ${ }^{5}$

Perhaps the least certain assumption of this model for the mechanism of $\mathrm{C}$ addition is that availability of $\mathrm{N}$ will have a stronger effect on introduced than on native species. This assumption is consistent with the association between high $\mathrm{N}$ and invasion. However, the assumption has not always been found to be true, especially when species are grown separately. The model also fails to account for possible direct effects of microbes on plants, such as through mycorrhizae. For example, if a mycorrhizal fungus translocates $\mathrm{N}$ to its plant host, this could alleviate decrease in availability of $\mathrm{N}$ in the soil.

Testing the efficacy of $\mathrm{C}$ addition as a countermeasure to the spread of introduced species of plants is of high societal interest because of the widespread elevation of $\mathrm{N}$ availability due to agriculture and pollution and of the potential advantages of $\mathrm{C}$ addition over other methods of control. In some regions $\mathrm{N}$ deposition following the burning of fossil fuels has caused major changes in vegetation that might be reversed, if desired, by reducing $\mathrm{N}$ availability back to levels before human-caused deposition. Much of the area available for restoration of some types of natural grasslands that have been made rare is on former agricultural fields, where $\mathrm{N}$ availability is typically elevated. These and other widespread, human-caused increases in $\mathrm{N}$ availability increase the likelihood that many introduced species have become widespread in part because they respond positively and strongly to high $\mathrm{N}$.

If effective, $\mathrm{C}$ addition could have important practical advantages over other methods for the control of invasive species. Because $\mathrm{C}$ addition is expected to control whole sets of introduced species, it could replace multiple and sometimes conflicting efforts to control individual introduced species. It could also replace the use of herbicides. If specific 
a) underlying relationships

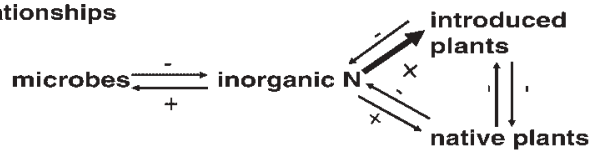

b) expected effects of carbon addition

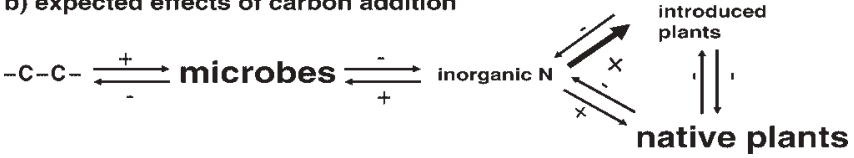

Figure 1. a, Relationships underlying the hypothesized mechanism by which carbon addition might counter the spread of introduced species of plants in a terrestrial habitat. The thicker arrow is intended to show that effects of high availability of nitrogen $(\mathrm{N})$ must be greater on introduced than on native species. b, Expected effects of amending the soil with a low- $\mathrm{N}$ metabolic substrate for soil bacteria or fungi. Changes in type size between the two panels show the expected increases or decreases in abundances of microbes, $\mathrm{N}$, and plants.

techniques such as twice-yearly applications of sawdust are effective, this could greatly reduce the cost and controversy over control.

Experiments with $\mathrm{C}$ addition are also of theoretical interest. A leading hypothesis to explain the spread of introduced species, or its lack, is biological resistance, that competition from native species on the same trophic level and predation by native generalists on the next trophic level reduce the growth and survival of introduced species. A main reason to expect that native species will outcompete introduced ones is that the natives are locally adapted. Recent, marked changes in environmental conditions are likely to change selection pressures and reduce the difference in fitness between native and introduced competitors. This could shift the balance of competition in favor of the latter, especially if conditions have changed to be more like those in their native range. Human-caused rise in $\mathrm{N}$ availability may be an example of such change, and, if reversing the rise reverses the spread of introduced species, this would support the hypothesis.

Published research on $\mathrm{C}$ addition to control introduced plants dates at least to $1994,{ }^{6}$ although the technique was used earlier as a way to investigate nutrient relations ${ }^{7}$ or increase rates of succession. ${ }^{8}$ The purpose of this review is to catalog the results of these last two decades or so of research on $\mathrm{C}$ addition and use them to address three questions: 1) Does $\mathrm{C}$ addition reduce $\mathrm{N}$ availability to plants? 2) Does it reduce the abundance of introduced plants? 3) Does it increase the abundance of natives?

\section{Findings}

\section{Range of Studies}

Most of the 55 relevant studies found (see online materials [www.srmjournals.org] for details of search methods and tabulations of studies) focused on a few major vegetation types and regions. A plurality of studies had been conducted on prairies of central North America (15 studies exclusively on prairies). Relatively large numbers of studies had also been conducted on mixed shrublands and grasslands of the intermontane United States (9), grasslands and heathlands in Europe that seem likely to be human-caused (8), and Mediterranean-type grasslands and shrublands in coastal California and southern Australia (7).

Many but not most studies added $\mathrm{C}$ exclusively as sucrose (21). Nine studies added exclusively sawdust, three added only a blend of sucrose and sawdust, and five compared separate additions of sucrose and sawdust. Only a few studies identified which types of trees sawdust was from. Other forms of $\mathrm{C}$ added were dextrose, glucose, cellulose, straw, bark, wood chips or fragments, urban wood waste, and leaf litter. Amounts of $\mathrm{C}$ added varied by two orders of magnitude, from 0.02 to 6.5 pounds C/yard $2 /$ year $(0.01-2.5 \mathrm{~kg} \mathrm{C}$ / $\mathrm{m}^{2} /$ year), with from 1 to 10 applications per year. Most studies (31) added C only once or over only 1 year, but at least nine continued applications for 3 years or more, and one for 10 years. Several studies continued measurements of effects for 1 year after applications ended, and one for 2 years after.

\section{Effects of C Addition on N Availability and Other Soil Characteristics}

Nearly all studies found that $\mathrm{C}$ addition reduced likely availability of $\mathrm{N}$ to plants (online materials, Table 1 ). The most common measurements of plant-available $\mathrm{N}$ were concentrations of $\mathrm{NO}_{3}$ and $\mathrm{NH}_{4}$ in extracts of soils in $\mathrm{KCl}$. Standing concentration of $\mathrm{NO}_{3}$ was often at least $50 \%$ less in soils amended with $\mathrm{C}$ (online materials, Table 2). Concentration of $\mathrm{NH}_{4}$ tended to show less effect of $\mathrm{C}$ addition and, unlike $\mathrm{NO}_{3}$, was sometimes found to be higher in plots with added $\mathrm{C}$ than in those without (e.g., Corbin and D'Antonio 2004; Iannone and Galatowitsch 2008; see online materials for references cited under Findings). However, no study reported higher total concentrations of inorganic $\mathrm{N}$ in amended than in control soils. The six studies that reported no significant effect of $\mathrm{C}$ addition on $\mathrm{N}$ availability each measured either only standing concentration of inorganic $\mathrm{N}$ or only net $\mathrm{N}$ mineralization; they shared no obvious similarities in experimental system or type or amount of addition. Other observed effects of $\mathrm{C}$ addition on $\mathrm{N}$ availability included decreases in amount of inorganic $\mathrm{N}$ absorbed on resin and in $\mathrm{N}$ mineralization, and increases in microbial $\mathrm{C}$ and $\mathrm{N}$, in density of microbes, and in production of $\mathrm{CO}_{2}$ in soil. All these effects are consistent with an increase in immobilization of $\mathrm{N}$ by soil microbes, the expected effect of $\mathrm{C}$ addition (Fig. 1).

These effects of $\mathrm{C}$ addition on soil $\mathrm{N}$ sometimes increased with repeated applications and generally decreased within months after applications stopped. For example, Young et al. (1996) saw little effect of sucrose on standing concentration of inorganic $\mathrm{N}$ until the second year of applications, and Michelson et al. (1999) found a positive effect on microbial $\mathrm{C}$ after 5 but not 2 years of applications. At least six studies documented decrease in effects of $\mathrm{C}$ on $\mathrm{N}$ within 
1 year after applications stopped (online materials, Table 2), although at least one (Blumenthal et al. 2003) reported no decrease within 2 years. There was little evidence that effects decreased as long as applications continued. Only one field study appears to have found that $\mathrm{C}$ addition reduced availability of phosphorus (Michelson et al. 1999).

Additions of $\mathrm{C}$ were also observed to affect the composition of soil biota. Biederman et al. (2008) reported increases in the abundance of bactivorous and several other functional groups of nematodes following application of wood waste, while Nieminen (2009) found a decrease in abundance of bactivorous nematodes in soil amended with sucrose, both opposite to expected changes in the relative abundance of bacteria and fungi with availability of lignin versus labile C. A detailed laboratory study by van der Wal et al. (2006) suggested that microbial decomposition of sawdust began with digestion of cellulose and hemicellulose on the surface of wood particles, and that additions of cellulose and sawdust favored similar soil biota, and glucose a different biota. Larger effects of $\mathrm{C}$ addition on nutrient cycling in the soil are further suggested by at least one finding that addition decreased decomposition of litter (Hunt et al. 1988).

A number of studies reported that $\mathrm{C}$ addition increased soil moisture (not noted in online materials, Table 2). This could be an effect of decrease in plant mass and hence uptake of water, of increase in organic matter in the soil, or of decrease in evaporation from the soil surface in the case of surface applications of sawdust or other wood products. Tilling in such applications can produce different results than applying the same applications to the surface (e.g., Biederman and Whisenant 2009). There does not yet seem to be enough information to indicate whether any of these differences are consistent, but they could suggest that effects of additions of sawdust may be due at least in part to changes in availabilities of resources other than $\mathrm{N}$.

\section{Effects of C Addition on Introduced Plants}

Effects of $\mathrm{C}$ addition on introduced species have been less consistent than those on soil $\mathrm{N}$, but still mainly negative. Of the 30 studies that separately reported effects of C addition on species unambiguously identified as introduced in the context of the experimental system, 20 found generally negative effects, nine found no effect, and one found a positive effect (online materials, Table 1 ). The most commonly reported negative effects were on aboveground mass and cover, which were often reduced by $30 \%$ or more (online materials, Table 2). Other negative effects included decreases in mass per plant, density, survival of planted seedlings, emergence of added seeds, tillering, height, seed production, and leaf $\mathrm{N}$ concentration. Negative effects increased with subsequent years of applications in at least one case (Rowe et al. 2009), and diminished the year after treatments ended in at least one case (Averett et al. 2004). In most cases, the introduced species present or measured were mostly annuals or biennials, although negative effects were noted on perennial introduced grasses in at least three studies (Perry et al. 2004; Gendron and Wilson 2007; Iannone and Galatowitsch 2008).

The studies that found no effect of $\mathrm{C}$ addition on introduced species consisted of all five studies in which addition was combined with burning, grazing, or mowing, one study that measured effects only on an introduced shrub (Cassidy et al. 2004), one study that measured only effects on germination (Monaco et al. 2003), one study that used a unique application of bark mulch and eucalyptus leaves (Cione et al. 2002), and one study that did not differ in obvious ways from those that reported negative effects (Corbin and D'Antonio 2004). This suggests that $C$ addition may have little additional effect on introduced species in systems that are also subjected to periodic removals of biomass, but also points out that few studies have tested effects on woody introduced species.

The study that found a positive effect of $\mathrm{C}$ addition on introduced species was the only one on mine spoils. Smith et al. (1986) also found positive effects of $\mathrm{N}$ addition on native species in this study and concluded that the positive effects of adding sawmill residue of mixed bark, chips, and sawdust were probably due to increased infiltration of water.

\section{Effects of C Addition on Native Plants}

Effects of $\mathrm{C}$ addition of native plants have been both positive and negative, with somewhat more studies finding negative than positive effects. The 41 studies that separated out and reported effects on native species variously found the following (online materials, Table 1): generally positive effects—six studies; mixed positive and null effects-three; mixed positive and negative effects-four; no effect-13; transient negative effects-two; mixed null and negative effects-two; weak generally negative effects-one; or generally negative effects- 10 .

Three of the six studies with generally positive effects began with largely unvegetated land and seeded or planted natives (Smith et al. 1986; Young et al. 1996; Kardol et al. 2008) but were otherwise very different from one another (online materials, Table 2). The other three studies were all on the same system (Prober et al. 2005; Smallbone et al. 2007; Prober and Lunt 2009), in which natives were perennial grasses or forbs.

Of the seven studies with mixed positive and null or negative effects, two showed positive effects only when natives were subject to competition from introduced species (Corbin and D'Antonio 2004; Perry et al. 2004), as expected from the model of underlying relationships (Fig. 1). One study each showed positive effects on native perennials but not on native annuals (Rowe et al. 2009), on perennials but not on annual forbs (McLenden and Redente 1992), on a tree but not on two perennial grasses (Niemenin 2009), of adding bark but not straw (Zink and Allen 1998), and only in more recently abandoned fields (Paschke et al. 2000). Effects were not statistically significant in this last study; each of the others began with bare soil. 
The 13 studies with mixed null and negative effects, weak generally negative effects, or generally negative effects included all three studies in largely natural systems not subjected to major disturbance that reported effects on natives, none of the studies in former crop fields, one study of a restored gravel pit with $80 \%$ cover of planted native grasses (Seastedt and Suding 2007), seven studies in which only natives were present, and two studies in which it was not clear if only natives were present (Miller et al. 1991; Bleier and Jackson 2007). In both of the studies with mixed null and negative effects (Shaver and Chapin 1980; Blumenthal 1999), effects were negative only on monocots. In at least two cases, sucrose had stronger effects than sawdust (Yarie and Van Cleve 1996; Bleier and Jackson 2007).

\section{Conclusions}

Research to date suggests that additions to soil of either sugar or sawdust in amounts of 0.3 pounds $\mathrm{C} / \mathrm{yard}^{2} /$ year or more $\left(0.1 \mathrm{~kg} / \mathrm{m}^{2} /\right.$ year or more $)$ are very likely to reduce availability of $\mathrm{N}$ to plants in many temperate or boreal systems; effects in tropical systems appear untested. Effects of $\mathrm{C}$ addition on soil $\mathrm{N}$ may build up over at least 2 years. They are likely to persist for at least 5 years as long as additions continue, but also to disappear within a few months to 2 years after additions stop.

Adding $\mathrm{C}$ as sugar or sawdust is also likely to reduce the abundance of introduced species in many systems. C addition seems more likely to negatively affect annuals than herbaceous perennials, and graminoids than forbs; effects on woody species are largely untested. $\mathrm{C}$ addition may have little additional effect on introduced species in systems that are also managed by grazing, burning, or mowing.

$\mathrm{C}$ addition is less certain to increase the abundance of native species. It may be more likely to do so when competition from introduced species is more intense, and in systems that have previously been cleared and enriched in $\mathrm{N}$ by human activity than in less disturbed systems. Whether $\mathrm{C}$ addition has stronger negative effects on the introduced than on the native plant species in a system, as required for addition to benefit natives, may largely depend on whether the introduced species tend to be annuals and the natives perennials.

Based on current knowledge, managers should consider using applications of sawdust as a way to control introduced species in grasslands and shrublands where burning and mowing are not being used. However, individual trials in each system will be needed to test whether applications will have positive effects on native plants.

\section{Acknowledgments}

I thank Ed Vasquez and Tom Monaco for organizing this special feature on invasive plants. Research was supported by USDA grant CREES 2006-34439-17024, in collaboration with the California State Parks and the US National Park Service. This is a contribution from the University of California Bodega Marine Laboratory.

\section{References}

1. Alpert, P., and J. L. Maron. 2000. Carbon addition as a countermeasure against biological invasion by plants. Biological Invasions 2:33-40.

2. Blumenthal, D. M. 2009. Carbon addition interacts with water availability to reduce invasive forb establishment in a semi-arid grassland. Biological Invasions 11:1281-1290.

3. Blumenthal, D. M., N. R. Jordan, and M. P. Russelle. 2003. Soil carbon addition controls weeds and facilitates prairie restoration. Ecological Applications 13:605-615.

4. Corbin, J. D., and C. D. D'Antonio. 2004. Can carbon addition increase competitiveness of native grasses? A case study from California. Restoration Ecology 12:36-43.

5. Szili-Kovács, T., K. Töröк, E. L. Tilston, and D. W. Hopkins. 2007. Promoting microbial immobilization of soil nitrogen during restoration of abandoned agricultural fields by organic additions. Biology and Fertility of Soils 43:823-828.

6. Morgan, J. P. 1994. Soil impoverishment: a little-known technique holds promise for restoring prairie. Restoration and Management Notes 12:55-56.

7. Shaver, G. R., and F. S. Chapin III. 1980. Response to fertilization by various plant growth forms in an Alaskan tundra: nutrient accumulation and growth. Ecology 61:662-675.

8. McLendon, T., and E. F. Redente. 1992. Effects of nitrogen limitation on species replacement dynamics during early secondary succession on a semiarid sagebrush site. Oecologia 91: 312-317.

Author is Associate Professor, Biology Department, University of Massachusetts, 611 N Pleasant St, Amberst, MA 01003, USA, palpert@bio.umass.edu. A full citation section can be found at http://www.srmjournals.org. 